\title{
The Inhibition of the Postnatal Rise of 2,3-Diphosphoglycerate in Newborn Lambs as a Result of Glucose Perfusion
}

\author{
HARRY BARD, JEAN-CLAUDE FOURON, AND JANIE PROSMANNE
}

Neonatology and Cardiology Services, Department of Pediatrics, Université de Montréal and Centre de Recherche Pédiatrique, Hôpital Sainte-Justine, Montreal, Quebec, Canada

\begin{abstract}
Due to the abrupt increase in 2,3-diphosphoglycerate (2,3-DPG) concentration in the newborn lamb, which begins soon after birth, this interval in development was considered an excellent period to test the hypothesis that glucose perfusions could inhibit 2,3-DPG synthesis. Ten newborn lambs were divided into two groups and perfused either with glucose $(15 \mathrm{mg} / \mathrm{kg} / \mathrm{min})$ or physiologic saline $(45 \% \mathrm{NaCl})$ for 10 days. Blood gases, electrolytes, glycemia, $\mathrm{O}_{2}$ pressure at $50 \% \mathrm{Hb}$ saturation, and 2,3-DPG levels were compared in the two groups. Glucose levels remained significantly elevated during the first 3 days in the glucose perfused group. The $\mathrm{O}_{2}$ pressure at $50 \% \mathrm{Hb}$ saturation increased in both groups but was significantly lower in the glucose perfused group when determined on day 5 and 8. The postnatal increase in 2,3-DPG was significantly diminished in the glucose infused lambs, which suggests that glucose perfusion has an inhibiting effect on erythrocyte 2,3-DPG synthesis. (Pediatr Res 24: 470-472, 1988)
\end{abstract}

\section{Abbreviations}

2,3-DPG, 2,3-diphosphoglycerate

$\mathbf{P}_{50}, \mathbf{O}_{2}$ pressure at $50 \% \mathrm{Hb}$ saturation

Inasmuch as the level of 2,3-DPG within the red cell is a prime determinant of whole blood oxygen affinity, it seems appropriate to examine the factors involved in the regulation of this glycolytic intermediate. The newborn lamb can be considered an unique animal model that can be used to obtain information necessary for an understanding of how the concentration of red cell 2,3DPG varies in response to environmental perturbations. The 2,3-DPG changes during the perinatal period in sheep have been well described (1-3). There is little variation in 2,3-DPG levels in the fetus until after birth when there is then a rapid rise and then fall in 2,3-DPG. The low adult levels are reached around 40 days after birth. It is of interest to note that the same fetal red cells present at the end of gestation are capable after parturition of 7-fold increase in their DPG concentration, reaching a peak at around 7 days of age. This phenomenon results in a rapid decrease in oxygen $\mathrm{Hb}$ affinity before the amount of adult $\mathrm{Hb}$ is adequate enough to provide the low $\mathrm{O}_{2}$ affinity physiologically required.

During a recently reported study where glucose was infused intravenously into chronically catheterized fetal sheep for a

Received March 21, 1988; accepted June 14, 1988.

Dr. Harry Bard, Centre de Recherche Pédiatrique, Hôpital Sainte-Justine, 3175 Côte Ste-Catherine, Montreal, Quebec, H3T 1C5, Canada.

Supported by Grant MA 8118 from the Medical Research Council of Canada. period of 5 days, a significant increase in glucose concentration as well as significant decrease in 2,3-DPG was noted (4). It was suggested that changes in glucose concentration could possibly cause a decrease in 2,3-DPG as a result of metabolic alterations effecting the erythrocytes. Because of the rapid and marked increase in 2,3-DPG that begins soon after birth in the newborn lamb, this interval in development can be considered an excellent moment to test the hypothesis that glucose perfusions could inhibit 2,3-DPG synthesis. A study was therefore planned to perfuse glucose into newborn lambs from the day of birth for the first 10 days of life and compare the changes in 2,3-DPG levels as well as $\mathbf{P}_{50}$ to a similar group of control newborn lambs that would be perfused with physiologic saline.

\section{MATERIALS AND METHODS}

Ten mixed breed newborn lambs (Dorset and Suffolk) less than $24 \mathrm{~h}$ of age were used in this study. Under local anesthesia the external jugular vein was cannulated for infusion purposes and a catheter was placed in the carotid for blood sampling. They were divided into two groups. In the glucose perfusion group, $50 \%$ glucose in sterile water was infused intravenously with a Harvard pump starting with initial dose of $5 \mathrm{mg} / \mathrm{kg} / \mathrm{min}$. The dose was gradually increased over a 24-h period until 15 $\mathrm{mg} / \mathrm{kg} / \mathrm{min}$ was reached. The glucose perfusion lasted 10 days. A second group of control lambs were similarly perfused with saline $(45 \% \mathrm{NaCl})$ in the same volume and over the same period of time as the first group. The animals were confined in a limited area, not restrained, and were bottle fed a milk substitute for newborn lambs.

The arterial blood gases and $\mathrm{pH}$ were obtained on a Radiometre ABL 30 acid base analyzer. $\mathrm{Hb}$ and $\mathrm{O}_{2}$ saturation were determined by a Radiometre OSM2 Hemoximeter. The $\mathrm{P}_{50}$ was established on a fresh blood sample using a tonometer at $37^{\circ} \mathrm{C}$. Concentration of red cell 2,3-DPG was determined by the method of Keitt (5) and blood glucose was determined by the enzymatic method of glucose oxidase. Daily sampling was obtained for $\mathrm{Hb}$, electrolytes, inorganic phosphorus as well as $2,3-$ DPG and glycemia. The $P_{50}$ was determined on day $1,5,8$, and 10.

Data analysis. The two groups were compared by use of a Student's $t$ test. The overall significance for this comparison was set at 0.05 .

\section{RESULTS}

Figure 1 illustrates the changes in plasma glucose. There was a significant increase in glucose concentration in the group that was perfused with hypertonic glucose $(p<0.05)$. During the first $48 \mathrm{~h}$ after birth there was a significant decrease in glucose levels of the controls $(p<0.05)$. Significant differences in glycemia 
were found between the two groups on day 2 and 3 . From thereafter there were no significant differences in the two groups of animals.

Figure 2 demonstrates changes in the $P_{50}$. There was significant increase in $\mathrm{P}_{50}$ in both groups $(p<0.005$; controls and $p<0.02$; glucose perfused); however, glucose-perfused animals had a significantly lower red cell $P_{50}$ levels on days 5 and 8 when compared to the controls. Figure 3 illustrates the differences in 2,3-DPG concentration in the two groups of animals studied. There was a very significant increase in 2,3-DPG in the controls during the saline infusions $(p<0.01)$ whereas the 2,3-DPG levels increased significantly though less in the glucose-perfused group $(p<0.05)$.

\section{Plasma glucose}

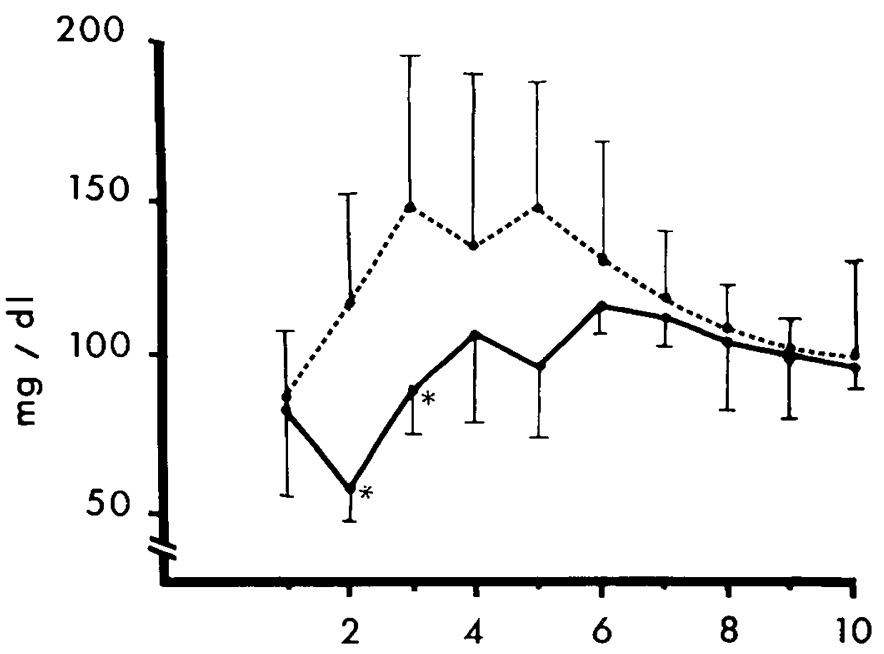

\section{Days}

Fig. 1. Comparison of the mean blood glucose \pm SD between the glucose perfused group (...) and the control group (---). ${ }^{*} p<0.05$ compared to the controls on the same day.

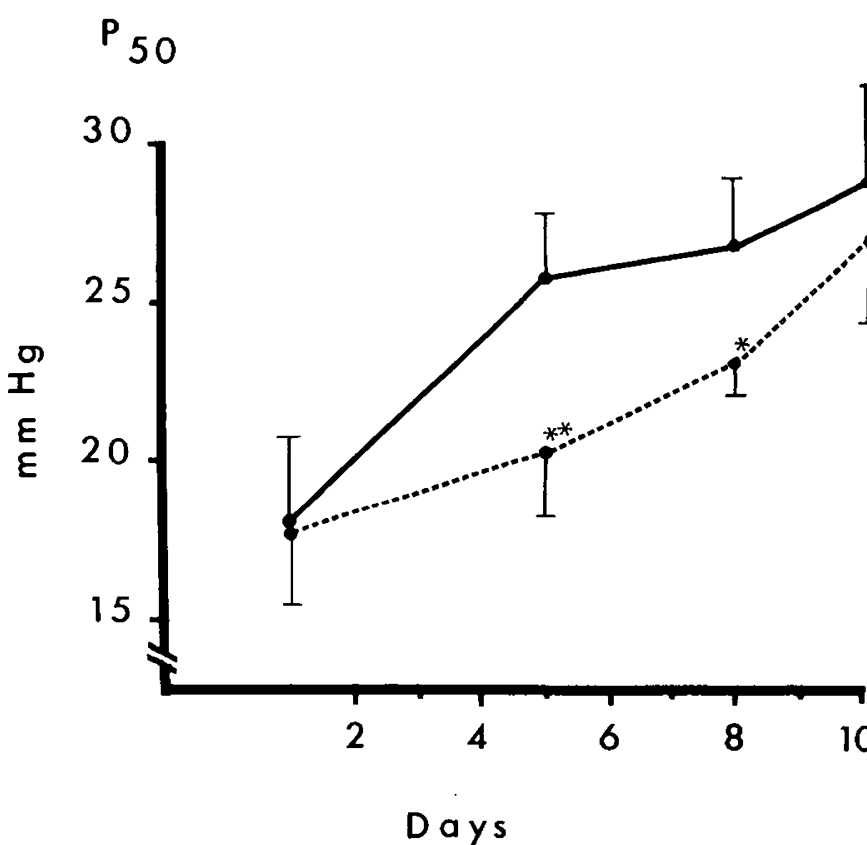

Fig. 2. Comparison of the mean $\mathrm{P}_{50} \pm \mathrm{SD}$ between the glucose perfused group (...) and the control group $(---){ }^{*} p<0.05 ;{ }^{* *} p<0.01$ compared to controls on the same day.

\section{2,3 DPG}

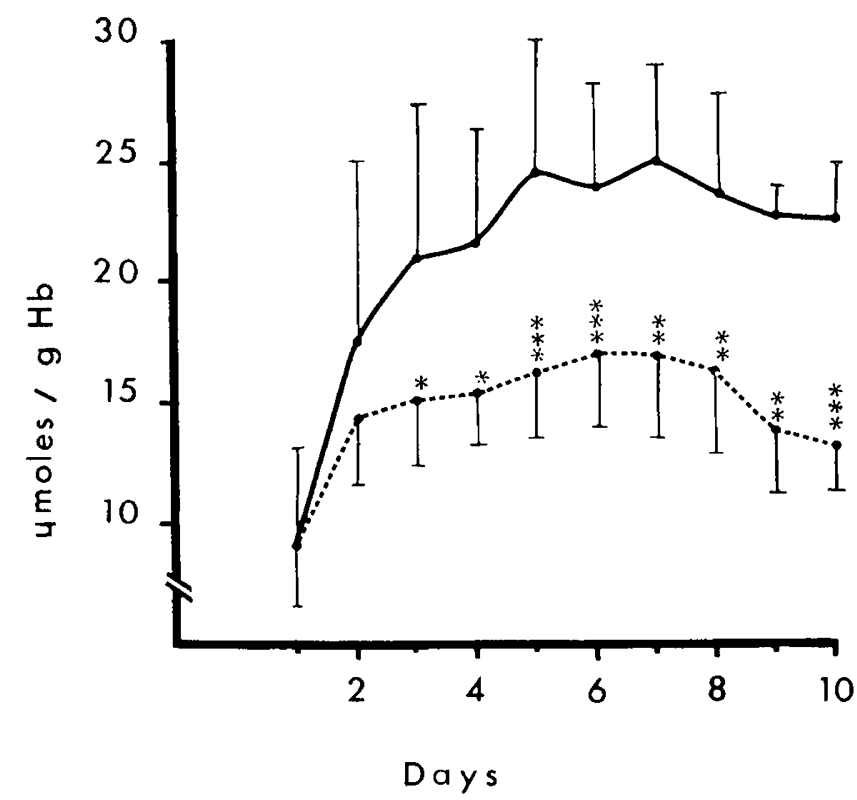

Fig. 3. Comparisons of the mean 2,3-DPG \pm SD between the glucose perfused group (...) and the control group $(---) .{ }^{*} p<0.05,{ }^{* *} p<0.01$, ${ }^{* * *} p<0.001$ compared to the controls on the same day.

There was little change in 2,3-DPG in the glucose-infused animals after the 2nd day whereas 2,3-DPG levels increased in the controls so that the differences between the two groups became significant and remained so until the end of the experiment.

There were no significant differences in blood gases and acid base balance, inorganic phosphorus, and electrolytes between the two groups of animals studied (data not shown). All values remaining within the physiologic limits.

\section{DISCUSSION}

As expected there was a significant increase in glycemia in the glucose-perfused group during the first 3 days of the study. Beyond the $3 \mathrm{rd}$ day the differences were no longer significant and this could possibly be due to the insulin response in the glucose-perfused group. Others using the same model have shown a rapid increase of insulin levels during concentrated glucose perfusion (6).

The effects of 2,3-DPG on the molecular mechanism responsible for the postnatal decrease in oxygen affinity are different in sheep and humans. In sheep, the fetal $\mathrm{Hb}$ is replaced by the adult type that has an intrinsically lower $\mathrm{O}_{2}$ affinity. The 2,3-DPG interacts very minimally with either of the $\mathrm{Hb}$. The transient rapid increase in 2,3-DPG observed in the neonatal sheep red cell exert their effects on the oxyhemoglobin-dissociation curve mainly by a Donnan-mediated decrease in red cell $\mathrm{pH}(2)$. In the human, 2,3-DPG binds to both fetal and adult-type $\mathrm{Hb}$ with a higher affinity for the latter. The differences in the affinity of fetal and adult $\mathrm{Hb}$ for 2,3-DPG account exclusively for the postnatal shift of the oxygen-dissociation curve of human blood (7).

The physiologic postnatal decrease in $\mathrm{O}_{2}$ affinity in newborn lambs can only be partially accounted for by the increase in adult $\mathrm{Hb}$. The major cause during the 1st wk after birth appears to be initially due to the high 2,3-DPG concentrations, which act both through its effect of lowering intracellular $\mathrm{pH}$ and through its direct interaction with $\mathrm{Hb}(2)$. In the previously reported fetal study, the decrease in 2,3-DPG had no detectable effect on fetal $P_{50}$ (4). This was due to the fact that in this species, where the fetal red cell has a low level of 2,3-DPG, the decrease in 2,3 - 
DPG was balanced by an increase in the amount of adult $\mathrm{Hb}$ as a result of the naturally occurring switchover from fetal to adult $\mathrm{Hb}$ synthesis. In our study, the $\mathbf{P}_{50}$ increases significatively in both groups but there is a lower $P_{50}$ on day 5 and 8 in the glucose-infused animals compared to the controls. This can be accounted for by their lower levels of 2,3-DPG. But at 10 days of age the difference in the two groups of this study was no longer significant. This could be explained by the dominant effect on $P_{50}$ in both groups of animals of the increased amounts of adulttype $\mathrm{Hb}$ at 10 days of age (3). The adult type $\mathrm{Hb}$ in this species, in contrast to that of humans, has a very low $\mathrm{O}_{2}$ affinity without requiring the addition of cofactors (7).

Blood glucose variations have been implicated in several studies in the regulation of 2,3-DPG. In humans a report describing diabetic hyperglycemic patients showed a concomittant decrease in 2,3-DPG during treatment (8). When human erythrocytes are incubated in a medium containing increased glucose concentration the level of 2,3-DPG concentration decreases. This is the result of metabolic changes within the red cell that increase the activity of the polyol pathway (9). These in vitro studies, the fetal experiments, and the findings in this report all suggest that glucose infusion can produce changes in red cell metabolism resulting in a decrease in 2,3-DPG level.

In a report where varying concentrations of glucose were infused constantly during a period of $6 \mathrm{~h}$ in a newborn lamb to produce a state of equilibrium in the plasma glucose concentrations, it was shown that under steady state conditions endogenous glucose production rates were significantly reduced when the glucose infusion rate increased (6). This could be a result of glucose loading causing an inhibition or deactivation of the hepatic gluconeogenic enzymes namely the glucose 6 phosphatase (10). Could similar phenomena occur within the red cell? Exogenous glucose could have both a suppressing effect on 2,3DPG synthesis by inhibiting the phosphorylation of glucose as well as increasing the activity of the polyol pathway. It remains to be demonstrated if glucose infusions during the human neonatal period could suppress 2,3-DPG synthesis and thus alter $\mathrm{Hb}$ $\mathrm{O}_{2}$ affinity. If it were so it could then be a confounding factor in the increased mortality and morbidity of very low birth weight newborn infants because these high risk infants are prone to hyperglycemia as a result of glucose perfusion (11).

\section{REFERENCES}

1. Bard H, Fouron JC, Robillard JE, Cornet A, Soukini MA 1978 Red cell oxygen affinity in fetal sheep: role of 2,3-DPG and adult hemoglobin. J Appl Physiol 45:7-10

2. Battaglia FC, McGaughey H, Makowski EL, Meschia G 1970 Postnatal changes in oxygen affinity of sheep red cells: a dual role of diphosphoglyceric acid. Am J Physiol 219:217-221

3. Bard H, Fouron JC, Grothe AM, Soukini MA, Cornet A 1976 The adaptation of the fetal red cells of newborn lambs to extrauterine life: the role of 2,3diphosphoglycerate and adult hemoglobin. Pediatr Res 10:823-825

4. Bard H, Fouron JC, De Muylder X, Ducharme G, Lafond JS 1986 Myocardia function and hemoglobin oxygen affinity during hyperglycemia in the fetal lamb. J Clin Invest 78:191-195

5. Keitt AS 1971 Reduced nicotinamide adenine dinucleotide-linked analysis of 2,3 diphosphoglyceric acid: spectrophotometric and fluorometric procedures. J Lab Clin Med 77:470-475

6. Cowett RM, Susa JB, Oh W, Schwartz R 1978 Endogenous glucose production during constant glucose infusion in the newborn lamb. Pediatr Res 12:853857

7. Bunn HF 1981 Evolution of mammalian hemoglobin function. Blood 58:189197

8. Standl E, Kolb HJ 1973 2,3-Diphosphoglycerate fluctuations in erythrocytes reflecting pronounced blood glucose variation. Diabetologia 9:461-466

9. Travis SF, Morrison AD, Clements RS Jr, Winegrad AI, Oski FA 1971 Metabolic alterations in the human erythrocyte produced by increases in glucose concentration. The role of the polyol pathway. J Clin Invest 50:21042112

10. Katz J, McGarry JD 1984 The glucose paradox. Is glucose a substrate for liver metabolism? J Clin Invest 74:1901-1909

11. Pildes RS 1986 Neonatal hyerglycemia. J Pediatr 109:905-907 